\title{
Commentary
}

\section{Where do we go from here? A comment on 'Emotional processing in a ten-session general psychiatric treatment for borderline personality disorder: A case study'}

KENNETH R. SILK, Department of Psychiatry, University of Michigan Health System, Rachel Upjohn Building-BOx 5769, 4250 Plymouth Road, Ann Arbor, MI, 48109-2700, USA

In 'Emotional processing in a ten-session general psychiatric treatment for borderline personality disorder: A case study', the author presents the situation where, after 10 sessions of a modified form of General Psychiatric Management (GPM), the patient not only fails to improve but actually appears to be trending in the direction of clinical deterioration, especially in her appreciation and expression of distress. The other two commentaries discuss possible reasons for this lack of improvement. I will address a straightforward and everyday clinical dilemma, i.e. where does the clinician go from here. The patient has not only failed to make progress but appears to be deteriorating. Then what does the clinician do?

The first decision point is to call in a colleague either to consult directly with the patient and the clinician or for the consultant to have a conversation with the clinician alone. These are patients that are not only very difficult to treat, but very difficult to treat by oneself. Bringing in another colleague with whom to confer about the case can add a level of objectivity that perhaps has gotten lost or distorted in the complex transferentialcountertransferential situations that often occur in treatment with these patients (Gabbard \& Wilkinson, 1994; Gunderson, 2001). While GPM would suggest that the failure to improve is probably related to an interpersonal 'event' between the therapist and the patient (Gunderson \& Links, 2014), it may only be in an open discussion with a non-judgmental colleague that understanding more completely what that interpersonal event could have been might be clarified. A glance at Figure 2 of the case study would suggest directing one's attention to events of sessions 3 through 6 (Berthoud, 2015). After session 3 there was a deterioration of the working alliance (even if not statistically significant) accompanied by a dramatic increase in global distress and some increase in fear and shame. Examining those 4 sessions in more detail could lead to a better appreciation of what might have been some of the interpersonal stressors that perhaps were not seen at that time they were occurring.

The second decision is whether there should be some consideration of changing the patient's pharmacologic regimen. The author writes 'Adjunct pharmacotherapy was used to aid with anxiety and her difficulty sleeping', but we do not know 
which specific psychopharmacologic agent(s) were employed. While there is lack of clarity as to which pharmacologic agents might be most useful (and most useful implies moderately effective at best) in borderline personality disorder (BPD) (Duggan, Huband, Smailagic, Ferriter, \& Adams, 2008; Saunders \& Silk, 2009; Stoffers et al., 2010), this does not mean that one should avoid psychopharmacology. But it should be used modestly with limited expectations. If there were sleep disturbances in addition to anxiety, it would in the long run be wiser clinically if the sleep and the anxiety could be modified by a single medication and preferably not a medication from the benzodiazepine or its near-neighbor (i.e. z-drugs) class. Thus there might be some wisdom in considering a low-dose of a somewhat sedating atypical antipsychotic (Saunders \& Silk, 2009; Silk \& Feurino III, 2012). There is some evidence for effectiveness of aripiprazole (Nickel et al., 2006) or olanzapine (Zanarini et al., 2012), or, most recently, quetiapine (Black et al., 2014), in these situations in patients with BPD. A low-dose atypical antipsychotic might also help with what was described as 'schizotypal traits'. Two caveats are worth mentioning: (1) the dose used should be low-dose, and (2) only one of the medications from this class be used. There is no evidence for the effectiveness of multiple medications from within the same pharmacologic class in this diagnostic group. The patient is a young woman with self-esteem and body-image issues, and thus one needs to be cognizant of and sensitive to potential weight gain (Silk, 2011).

Another decision, and one that may be more complicated than the psychopharmacologic one, is whether there should be a change in treatment approach away from GPM or the addition of other psychotherapeutic interventions to the GPM. The answer to this question hopefully would be informed by the discussion and consultation with a colleague as mentioned above. Does the patient need a therapy even more structured than GPM? On one hand she appears competent in some areas, but that competency may at best be a pseudocompetency, and she may need more coping skills and more specific work on cognitive processing that may be more directly addressed through DBT (Linehan et al., 2006) or CBT (Davidson et al., 2006). On the other hand, and this may go back to appreciating in more detail the interpersonal events that occurred in the therapy between sessions 3 and 6 , a greater focus on mentalization may be needed (Bateman \& Fonagy, 2008), either through adding more emphasis on mentalization in the GPM itself or directing the patient to a more mentalization-specific focused treatment. I would not at this juncture suggest a transference-focused therapy approach because I surmise that it is a lack of coping skills and mentalization that appear to be at the heart of this woman's difficulties that are most likely being experienced quite acutely in the therapy but are probably also experienced more or less intensely in many situations throughout any given day.

\section{References}

Bateman, A., \& Fonagy, P. (2008). 8-year follow-up of patients treated for borderline personality disorder: mentalization-based treatment versus treatment as usual. American Journal of Psychiatry, 165, 631-638.

Berthoud, L. (2015). Emotional processing in a ten-session general psychiatric treatment for borderline personality disorder: a case study. Personality and Mental Health, 10.

Black, D. W., Zanarini, M. C., Romine, A., Shaw, M., Allen, J., $\&$ Schulz, S. C. (2014). Comparison of low and moderate doses of extended-release quetiapine in borderline personality disorder: a randomized, double-blind, placebocontrolled trial. American Journal of Psychiatry, 171, 1174-1182.

Davidson, K., Norrie, J., Tyrer, P., Gumley, A., Tata, P., Murray, H., \& Palmer S. (2006).The effectiveness of cognitive behavior therapy for borderline personality disorder: results from the borderline personality disorder study of cognitive therapy (BOSCOT) trial. Journal of Personality Disorders, 20, 450-465.

Duggan, C., Huband, N., Smailagic, N., Ferriter, M., \& Adams, C. (2008). The use of pharmacological treatments for people with personality disorder: a systematic review of randomized controlled trials. Personality and Mental Health, 2, 119-170.

Gabbard, G. O., \& Wilkinson, S. M. (1994). Management of countertransference with borderline patients. Washington, DC: American Psychiatric Press. 
Gunderson, J. G. (2001). Borderline personality disorder. a clinical guide. Washington DC: American Psychiatric Publishing, Inc.

Gunderson, J. G., \& Links, P. S. (2014). Handbook of good psychiatric management for borderline personality disorder. Arlington, VA: American Psychiatric Publishing.

Linehan, M. M., Comtois, K. A., Murray, A. M., Brown, M. Z., Gallop, R. J., et al. (2006). Two-year randomized controlled trial and follow-up of dialectical behavior therapy vs therapy by experts for suicidal behaviors and borderline personality disorder. Archives of General Psychiatry, 63, 757-766.

Nickel, M. K., Muehlbacher, M., Nickel, C., Kettler, C., Pedrosa, G. F., Bachler, E., Buschmann, W., Rother, N., Fartacek, R., Egger, C., Anvar, J., Rother, W. K., Loew, T. H., \& Kaplan, P. (2006). Aripiprazole in the treatment of patients with borderline personality disorder: a doubleblind, placebo-controlled study. American Journal of Psychiatry, 163, 833-838.

Saunders, E. F. H., \& Silk, K. R. (2009). Personality trait dimensions and the pharmacologic treatment of borderline personality disorder. Journal of Clinical Psychopharmaco$\log y, 29,461-267$.
Silk, K. R. (2011). The process of managing medications in patients with borderline personality disorder. Journal of Psychiatric Practice, 17, 311-319.

Silk, K. R., \& Feurino III, L. (2012). Psychopharmacology of personality disorders. In T. Widiger (Ed.), The Oxford handbook of personality disorders (pp. 713-724). Oxford, UK: Oxford University Press.

Stoffers, J., Völlm, B. A., Rücker, G., Timmer, A., Huband, N., \& Lieb, K. (2010). Pharmacological interventions for borderline personality disorder. Cochrane Database Systemic Review, 6, CD005653

Zanarini, M. C., Schulz, S. C., Detke, H., Zhao, F., Lin, D., Pritchard, M., Deberdt, W., Fitzmaurice, G., \& Corya, S. (2012). Open-label treatment with olanzapine for patients with borderline personality disorder. Journal of Clinical Psychopharmacology, 32, 398-402.

Address correspondence to: Kenneth R. Silk, Department of Psychiatry, University of Michigan Health System, Rachel Upjohn Building-B0x 5769, 4250 Plymouth Road, Ann Arbor, MI 48109-2700, USA. Email: ksilk@umich.edu 